\title{
Resúmenes de la Literatura Actual
}

\section{ESTUDIO DE LA FUNCION NEUROHIPOFISIARIA EN UN CASO DE DIABETES INSIPIDA, DURANTE 2 CICLOS GRAVIDO-PUERPERALES}

\author{
Dres. Edgard Cobo y Matilde de Bernal
}

\section{Resumen}

La diabetes insípida completa constituye un modelo eficaz para el estudio de la función neuro-hipofiisaria, ya que en ella la síntesis y secreción de hormona antidiurética están seriamente alteradas. Además, no se tienen datos muy concluyentes sobre el grado de alteración de la liberación oxitocina, la otra hormona neurohipofisiaria.

El objeto de esta comunicación es describir el análisis preliminar de algunos datos obtenidos por nosotros, en una paciente portadora de esta enfermedad, y estudiada durante el parto y la lactancia.

\section{Material y Métodos}

La paciente en mención, tenía 24 años de edad cuando se hizo el diagnóstico. En la actualidad tiene 32 años. En ese lapso, se estableció de manera absoluta el diagnóstico de diabetes insípida completa y además presentó 2 embarazos, con partos espontáneos de término.

El estudio de las actividades antidiurética, uterina y eyecto-láctea, se hizo utilizando métodos ya convencionales, que hemos descrito previamente (1).

\section{Resultados}

Los estudios relacionados con la liberación de hormona antidiurética, demostraron que no existía liberación significativa cuando la glándula neurohipofisiaria se estimuló con hipertonicidad del plasma (solución salina hipertónica, al 3\%), posición súbita de pies y administración I.V. de nicotina.

Los dos partos en los cuales practicamos registro continuo de la presión amniótica, demostraron la existencia de una actividad uterina baja. Sin embargo, fue suficiente para dilatar el cuello y expulsar 2 fetos vivos y normales en 6 y 8 horas, 0 sea en un lapso normal, en ambos partos, respectivamente.

En la lactancia, la glándula mamaria demostró una sensibilidad muy alta a la oxitocina. Se estableció además, que los estímulos que usamos: la succión del niño y la dilatación instrumental de galactóforos, produjeron respuestas mamarias comparables en forma, latencia y duración, a la de los casos normales.

\section{Comentario}

Estos resultados indican que en una paciente con diabetes insípida, el control del metabolismo de agua dependiente de la liberación de hormona antidiurética, está seriamente alterado; en cambio, la eyección láctea, fenómeno dependiente con exclusividad de la liberación de oxitocina, no lo está. Los partos, se presen- 
taron con actividad baja, pero fueron de duración y evolución normal.

La evidencia relacionada con el parto, no es muy concluyente para nosotros, ya que tenemos algunas evidencias experimentales que nos hacen dudar de lo oxitocina, como único elemento contralor de la actividad uterina, en el parto humano.

Concluímos, que estos resultados refuerzan nuestras observaciones pre- vias, acerca de la liberación diferencial de oxitocina y hormona antidiurética, dependiendo del estímulo que se emplee. En este caso, vemos como puede bloquearse una actividad (la antidiurética), con persistencia de la otra (la oxitócica).

\section{BIBLIOGRAFIA}

1 COBO, E., GAITAN, E., MIZRACHI, M., and STRADA, G.: "Neurohypophyseal Hormone release in the human.". Am. J. Obst. \& Gynec. 91: 905, 1965.

\section{ESTUDIO SIMULTANEO DE LAS ACTIVIDADES UTERINA Y EYECTO-LACTEA, DURANTE EL PARTO HUMANO}

\section{Dr. Edgard Cobo}

\section{Resumen}

El mecanismo que controla la iniciación y el desarrollo del parto, permanece aún desconocido. Durante los últimos 25 años se ha publicado una serie de evidencias que indicarían que la activación del útero en el parto, estaría controlada por la liberación de oxitocina, una hormona almacenada en el lóbulo posterior de la hipófisis.

Sin embargo, aún no está claramente establecido este hecho; en cambio, el papel de la oxitocina en el control de la eyección láctea está mucho más definitivamente aclarado. Más aún, el mioepitelio mamario es más sensible y específico a la acción de la oxitocina que el útero humano.

Por estas razones, diseñamos el estudio simultáneo de ambos órganos, durante el parto, aceptando que el mioepitelio mamario es un método finamente sensible de ensayo biológico, para inferir liberación de oxitocina endógena.

\section{Material y Métodos}

Se estudiaron 20 mujeres normales y una que presentaba diabetes insípida completa, durante el parto normal y espontáneo. En estas pacientes se realizó un estudio continuo de las presiones intraamniótica e intratraductal mamaria. Se midió el área debajo de las curvas de contracción registradas, obteniéndose valores que fueron denominados como "actividad uterina" y "actividad eyecto-láctea" respectivamente, los cuales a su vez fueron expresados en $\mathrm{mm} 2 / \mathrm{min}$. La respuesta de la glándula mamaria, que es más sensible y responde más específicamente que el útero a la administración de oxitocina, se usó como criterio la liberación de esta hormona. En todos los casos se determinó la sensibilidad de la glándula mamaria a la oxitocina.

\section{Resultados}

Del total de casos estudiados, 13 mostraron respuestas mamarias claras a la administración de 1 a 2 mu 
de oxitocina sintética en inyección I.V. única y de 1 a $2 \mathrm{mu} / \mathrm{min}$. en infusión continua, siendo seleccionadas por esta razón para realizar el estudio. Se encontró que la actividad uterina fue mayor durante el pre-parto que durante el embarazo y que aumentó exponencialmente al final del primer período y durante el segundo período del parto. Sin embargo, no apareció actividad eyecto-láctea significativa durante el parto, a pesar de que la glándula mamaria conservaba su capacidad para responder a dosis bajas de oxitocina.

\section{Comentarios}

En nuestro concepto, el mecanismo contralor del parto humano ha sido encarado de manera muy simplista. En efecto, se ha pretendido localizarlo en una sola glándula (la neurohipófisis) y atribuirlo a una sola hormona (la oxitocina). Los mecanismos responsables de los eventos reproductores importantes, son usualmente más complejos. Valgan como ejemplos: el ciclo menstrual y la lactancia.

De acuerdo con nuestras experiencias, $(1,2)$ y con las evidencias de otra índole, aportadas por varios autores, el parto sería un fenómeno en el cual están participando varios sistemas biológicos y varios factores biológicamente activos, además, o en lugar de, la oxitocina.

\section{BIBLIOGRAFIA}

COBO, E. J. Appl. Physiol. 24: 317 ; 1968.

2 COBO, E., DE BERNAL, M., QUINTERO, C. A., and CUADRADO, E. 101: 479; 1968.

\section{TROMBOFLEBITIS PERIFERICA VENOSA DURANTE EL EMBARAZO}

GURLL, N., HELFAND, Z., SALZMANN, E. F. y SILEN, W. (Beth Israel Hospital, Boston, Mass.). Amer. J. Surg., 121: 449-466, 1971.

El tratamiento de la tromboflebitis periférica venosa durante el embarazo presenta problemas difíciles que no aparecen bajo circunstancias normales. Debido a que los derivados cumarínicos constituyen moléculas pequeñas que fácilmente atraviesan la placenta, se ha considerado que los peligros para el feto hacen contraindicativo el uso de estas drogas. A la trombectomía generalmente sigue una re-trombosis y no se recomienda, excepto para el miembro masivamente hinchado con amenaza de gangrena. La ligación de la vena femoral se considera apropiada para la paciente con tromboflebitis en la pantorrilla, sufrida al comienzo del embarazo, quien requeriría hospitali- zación prolongada en el caso de ser tratada con heparina.

El tratamiento no quirúrgico con descanso en la cama durante 507 días y administración intravenosa de heparina, la cual no atraviesa la placenta, está basado en consideraciones patofisiológicas de fondo. En un período de 4.5 a 5 años se han tratado siete pacientes con tromboflebitis profunda antepartum. La heparina se continuó después del parto hasta obtener efecto con los anti-coagulantes orales administrados en el momento del parto. Los antagónicos de las vitaminas se continúan entonces por 3 a 6 meses. La tromboflebitis durante el embarazo no es frecuente no obs- 
tante las similitudes fisiológicas de otros estados con una mayor incidencia de la enfermedad tromboembóli- ca (por ejemplo, el puerperio y durante la administración de drogas contraceptivas orales).

\section{MORTALIDAD MATERNA JUVENIL EN CHICAGO, 1956-1968}

LANE, R. E., y BROWN, M. (Northwestern Univ. Escuela de Medicina, Chicago Wesley Memorial Hospital, Chicago, III.). Illinois Med. 139: 337-340, 1971.

Desde 1956 hasta 1968, ocurrieron en Chicago 23 muertes maternas, excluyendo las muertes que ocurrieron en el Cook Country Hospital. 65\% de estas muertes tenían factores preventivos según el juicio del comité de mortalidad materna. De las pacientes que murieron, $60 \%$ eran solteras y $70 \%$ no eran blancas. La embolia pulmonar, la toxemia, la hemorragia, la infección, la anestesia y la enfermedad hematíe falciforme constituyeron causas de muerte en frecuencia descendente. Las condiciones resultantes de estas causas de muerte fueron la eclampsia (5), el aborto ilegal (4), la desproporción céfalopélvica (3), el parto vaginal no eventual (3), el embarazo ectópico (2), la rotura del útero (2), la repetición de la sección cesárea (2), el procedimiento Shirodkar (1), y la enfermedad hematíe (1). Los factores preventivos en las causas de muerte fueron el aborto ilegal, la falta de cuidado prenatal, el error en el juicio obstétrico, el error en la técnica de anestesia y la falta de consulta obstétrica.

Puesto que la mayoría de las pacientes eran solteras y no blancas, se presume que la causa básicamente predominante de las muertes en este grupo constituye la falla de la sociedad en cumplir con su responsabilidad de crear un ambiente donde los conocimientos y la madurez emocional de las mujeres jóvenes esté al nivel de su madurez física.

\section{CESAREA: TRANSVERSAL BAJA (Pfannenstiel) O INCISION EN LA LINEA MEDIA BAJA?}

TIMONEN, S., CASTREN, O. y KIVALO, I. (Hospital Central Universitario, Helsinki, Finlandia). Ann. Chir. Gynaec. Fenn. 59: 173-176, 1970.

Se compararon los procedimientos en una serie de 1.915 operaciones cesáreas, por incisión en la línea media baja ( 1.059 pacientes) y por incisión transversal baja, Pfannenstiel ( 856 pacientes). Se obtuvo un mejor resultado cosmético con la incisión transversal (abdominal) baja, pero se perdieron varios minutos. El tiempo transcurrido entre el comienzo de la operación hasta el momento del nacimiento del bebé fué de 4 minutos o menos en $56 \%$ de las operaciones cesáreas realizadas por incisión en la línea media, contra únicamente $28 \%$ en aquellas en las cuales la 
incisión realizada fue transversal. La mayor diferencia entre estos dos métodos parece encontrarse en el tiempo perdido desde el comienzo de la anestesia hasta el nacimiento. Durante este tiempo puede desarrollarse una acidosis fetal creciente. La mortalidad perinatal no fué mayormente influenciada, pero cuando el feto se asfixia o es prematuro las condiciones del recién nacido al ser medidas por las escalas de Apgar, fueron mejores en el grupo de incisión en la línea media. El resultado puede ser considerado como prueba en favor de una incisión en la línea media baja.

\section{RELACION ENTRE EL PESO DEL FETO Y EL NIVEL DE CREATININA DEL LIQUIDO AMNIOTICO}

DUMONT, M., PAGE, Y. y LANSAC, J. (Facultad de Medicina de Lyon, Lyon, Francia).

Lyon Med. 124: 757-760, 1970 (texto original en francés).

El examen del nivel de creatinina en el líquido amniótico ofrece información de primera calidad sobre el peso y el grado de madurez del feto. Por tanto, en algunos embarazos patológicos, éste sirve al médico para decidir entre la histerotomía y el parto inducido. Cuando el nivel de creatinina llega a $2 \mathrm{mg} / 100 \mathrm{ml}$., se puede deducir con certeza que el feto pesa por lo menos 2.500 gramos.

\section{LA PILDORA MENSUAL}

BERMAN, E. (Warner-Lambert, Instituto de Investigaciones, Morris Plains, N. J.)

J. Reproduct. Med. 5: 37-42, 1970.

El contraceptivo oral mensual ha sido utilizado en América Latina durante los últimos 4 años por más de 3.000 mujeres y ahora se encuentra siendo clínicamente investigado en los Estados Unidos. El desarrollo y algunos de los descubrimientos sobre este contraceptivo han sido revisados. El método se basa en el hecho de que la administración oral de quinestrol constituye un estrógeno de actividad prolongada. Después de su absorción, el quinestrol se almacena intacto en la grasa del cuerpo. Posteriormente es liberado de la grasa y posiblemente ejerce su acción por conversión en estradiol-etinilo, ya que este compuesto ha sido recuperado de la bilis, orina $y$ excrementos. Por lo tanto, una dosis simple de quinestrol administrada oralmente tiene más o menos el mismo efecto que una inyección intramuscular de un estrógeno de actividad prolongada.

El quinestrol de $2 \mathrm{mg}$. ha sido utilizado en combinación con acetato de quingestanol, $2.5 \mathrm{mg}$. o $5 \mathrm{mg}$. una vez cada 4 semanas o una vez cada mes calendario, sin tener en cuenta el momento de terminación de la hemorragia que generalmente se inicia 7 a 14 días después de la administración. El control cíclico fué bueno, con aumento normal o ligero de la longitud del ciclo y duración del flujo. Los efectos laterales fueron similares en tipo y frecuencia a aquellos 
reportados sobre contraceptivos orales convencionales. La tasa de embarazos fluctuó entre 0 y 1.6/100 añosmujer en pacientes de la clase educada superior o superior media, y en general, fué mejor aceptado por ellas que por pacientes de barriadas donde la tasa de embarazo fue tan alta como 5.8/100 años-mujer en un sólo estudio. Se recomienda un método adicional de contracepción para el primer ciclo de tratamiento ya que la combinación no ofrece protección adecuada hasta después de la segunda dosis.

\section{VAGINITIS POST-IRRADIACION}

PITKIN, R. M. y VAN VOORHIS, L. E. (Hospitaies de la Universidad de lowa, lowa City, lowa).

Radiology, 29: 417-421, 1971.

La vaginitis post-irradiación descarga vaginal con o sin hemorragia, dispareunia, eritema de la mucosa y, frecuentemente, una membrana blancuzca de ulceración real que progresa hasta convertirse en adherencias y eventualmente puede resultar en aglutinación vaginal es frecuente después de terapia de irradiación para carcinoma del cérvix. El estrógeno tópico facilita la recuperación de una te normal. En una evaluación controlada, "doblemente ciega", de los efectos clínicos del estrógeno tópico, se trataron 93 pacientes con crema dienestrol vaginal o placebo, durante 5 a 8 meses inmediatamente después de terminar la terapia de irradiación. Las pacientes tratadas con estrógeno, en controles comparativos, presentaron menor dispareunia, alteraciones generales en el epitelio vaginal $y$ estrechamiento del calibre vaginal en forma estadísticamente significativa. La diferencia en la incidencia y seriedad de la hemorragia vaginal no fue significativamente diferente entre los dos grupos. El coito, independientemente del tratamiento con estrógeno, fué asociado con un calibre vaginal casi normal pero no está clara la relación efecto-causa. El uso de estrógeno tópico después de la terapia de irradiación para carcinoma del cérvix puede esperarse que disminuya la incidencia de las complicaciones post-irradiación en la vagina.

\section{ESTIMULO DE LA OVULACION: PROBLEMAS PARA PREDECIR LA RESPUESTA A LAS GONADOTROPINAS}

HANCOCK, K. W., et. al. (Universidad de Leeds, Leeds, Inglaterra). Lancet 2: 482-485, 1970.

Se analizaron los resultados de 50 tratamientos con gonadotropinas humanas en 12 mujeres con fallas de ovulación. Tuvieron lugar 8 embarazos, incluyendo 5 nacimientos sencillos y 3 de mellizos biovulares. Se utilizó un régimen de dosificación creciente de gonadotropina menopáu- sica humana, controlado por medio de ensayos diarios de estrona urinaria. El aumento de la excreción de estrona durante la respuesta a la terapia siguió una curva de crecimiento logarítmico. Al hacer el recuento de los niveles de estrona contra el tiempo, se obtuvo una línea recta. La 
linealidad fue más consistente desde los 6 días incluyendo el momento máximo de estrógeno. Al determinar la declinación de la línea de regresión en aquellos ciclos que resultaron en embarazo, se descubrió que existía una diferencia importante entre la declinación en aquellos ciclos que produjeron un sólo hijo (0.136 cifra media) y aquellos de mellizos ( 0.235 cifra media). En el caso recientemente reportado sobre quíntuples, la declinación hubiera excedido de 0.3.

Si se confirman estos descubrimientos en series mayores, el uso de la declinación del registro de la línea de regresión de tiempo, el cual indica la tasa de aumento en producción de estrona, se ofrecería un medio para determinar la maduración folicular múltiple. En tales casos sería posible evitar las complicaciones del "síndrome de hiper-estimulación" y el embarazo múltiple en un orden inaceptable, al suspender la administración de la inyección luteinizante, gonadotropina coriónica humana ( $G$ $\mathrm{CH}$ ). Para lograr la ovulación sería necesario administrar la inyección luteinizante 48 horas antes del momento pico del estrógeno. Aunque el régimen de una dosis de $\mathrm{HMG}$ creciente es económico en el uso de gonadotropinas y en tiempo, ofrece peligros para predecir el momento pico del estrógeno. En todos los ciclos que muestran una respuesta, el máximo de excreción de estrona se obtuvo dentro de los $5 \pm 2$ días en que el estrógeno alcanzó $0.01 \mathrm{mgr} / 24$ horas. Por lo tanto, para la administración del HCG se ha escogido el quinto día después de que la excreción de estrona llega al nivel de $0.010 \mathrm{mg}$.

\section{SALPINGOPLASTIA: INFORME Y CLASIFICACION DE 115 OPERACIONES}

SIEGLER, A. M. (State University of New York - Downstate Medical Center, Brooklyn, N.Y.).

Obstet. Gynec. 34: 339-344, 1969.

Se ha propuesto la clasificación de los procedimientos de tuboplastia para permitir comparaciones más representativas; al efecto se realizaron 115 de dichas operaciones tubáricas. La clasificación está basada primordialmente en un análisis de laparotomías para la corrección de infertilidad causada por enfermedad tubárica.

Algunas mujeres fueron sometidas a laparotomía pero no a tuboplastia, ya sea debido a que no se encontró enfermedad tubárica o debido a que las alteraciones que se encontraron eran extensas. La tuboplastia incidental puede realizarse durante una laparotomía efectuada primordialmen- te para cualquier otra condición ginecológica. En lisis por adhesión, salpingolisis es el corte de las adherencias que ligan los conductos y los ovarios, o los conductos y las estructuras adyacentes o contiguas.

La salpingostomía bilateral homogénea es la creación, por cirugía, de una apertura en un conducto obstruído en diferentes sitios posibles, pero es esencial tener en cuenta si los conductos son o no tratados en forma similar. En la salpingostomía de la fimbria se ven los dos extremos o se encuentran las fimbrias invertidas una vez que se ha hecho una pequeña incisión en una oclusión terminal. En la salpingostomía ampular 
se hace un nuevo óstium claviforme en el borde terminal, lateral 0 antimesosalpingeal, de un conducto obstruído. En la salpingostomía ístmica, una resección del conducto que deja $5 \mathrm{cms}$. o menos y una luz angosta, resulta invariablemente en estenosis y oclusión posteriores.

Cuando se interrumpe la continuidad de un conducto debido ya sea a una ligación previa del conducto o a un defecto congénito, la anastomosis de los segmentos pequeños del conducto puede ser factible. La implan- tación uterotubaria se divide en tres etapas: preparación tubárica, preparación uterina e implantación. La tuboplastia unilateral se realiza debido a que el conducto opuesto no existe, 0 es normal, o requiere salpingectomía. Las diferentes tuboplastias en conductos opuestos se incluyen en el grupo "combinado". El resultado de las 115 operaciones indicó que de 17 mujeres que concibieron, 13 tuvieron nacimientos con vida. Los mejores resultados fueron obtenidos en el grupo de resección y anastomosis.

\section{HERPES DE LA VULVA}

DICKIE, E. G. (Laboratorio de Cancerología de Hawaii, Honolulú, Hawaii).

Obstet. Gynec. 34: 434-446, 1969.

La herpes de la vulva es probablemente la enfermedad del tracto genital femenino más dolorosa y que más incapacita, fuera de la enfermedad de inflamación aguda de la pelvis ("PI $\left.D^{\prime \prime}\right)$. No existe una terapia efectiva, aunque parece existir un aumento indudable en todos los tipos de infecciones por herpes en ambos sexos. El estudio consistió de 28 pacientes con herpes de la vulva, quienes fueron diagnosticadas clínica y citológicamente y luego tratadas.

Las ulceraciones comienzan como erosiones nuevas de 1 a $2 \mathrm{~cm} 2$. sobre las membranas mucosas labiales, que progresan y se juntan hasta que toda la mucosa labial se encuentra cubierta, en forma similar a una quemadura de segundo grado. De 4 a 5 días las ulceraciones comienzan a curar por intención secundaria de la periferia, lo cual toma de 10 a 20 días según la gravedad de la infección bacteriana.
Todavía se desconoce el factor de activación por el cual el virus de herpes DNA o RNA se estimula para reproducirse. Una vez activadas, todas las infecciones de herpes parecen seguir el mismo patrón o ciclo de vida, el cual se puede catalogar en 5 etapas: Etapa l, activación del virus ( 1 a 2 horas); Etapa II, reproducción del virus ( 24 a 48 horas); Etapa III, destrucción del tejido superficial (8 a 12 horas); Etapa IV, desactivización del virus ( 2 a 4 horas) y Etapa $V$, período de curación de la epidermis (2 a 3 semanas).

Citológicamente, las células multinucleares gigantes de diagnóstico deben ser diferenciadas de las células sinsitiales gigantes que se ven en histiocitos, trofoblastos, tejido de granulación, tumores malignos, células de anemia megaloblástica, células benignas asociadas con granulomas, sarcoideo, trauma, cuerpos extraños, y aglutinamientos celulares de adenocarcinoma. 
Los agentes terapéuticos deberán ser dirigidos hacia las Etapas I y II del proceso de reproducción a fin de poder controlar el herpes antes de que ocurra la destrucción del tejido superficial epidérmico. Después de la anestesia vulvar local con tetracaína (Pontocaína), se aplica generosamente una solución de película líquida de idoxuridina (Herplex) cada cinco minutos durante media hora. Se continúa con la Idoxuridina en la casa aplicándola cada media hora durante el período siguiente de 24 horas. Los analgésicos y sedantes orales se formulan generosamente. También se utiliza la gamma-globulina para posibles anticuerpos de herpes.
En los jóvenes, orientados más en forma sexual, de una población menos inhibida, existe una prevalencia aumentada de prácticas de Cunnilingus y Fellatio que pueden servir como medio conveniente para la transferencia de auto-inoculación de herpes simplex faciales o labiales hasta una zona menos conspicua, aunque obviamente más inconveniente, de la anatomía. La Idoxuridina se aproxima mucho a la configuración de timidina y produce un pseudo-virus que ni infecta ni destruye el tejido. Los estudios indicaron que el proceso de la enfermedad puede ser evitado si el tratamiento comienza dentro de los 2 primeros días. 